\title{
Five Facets for Effective English Language Teaching
}

Nani Babu Ghimire

\begin{abstract}
Effective English language teaching (ELT) is strongly related to dynamic teachers and creative learners as it enhances students' long lasting learning process. Students learn the taught matters successfully if the classroom is handled effectively focusing on child centered pedagogy with the use of modern information communication technology (ICT). The objective of this paper is to look at the different facets for effective ELT and to give some pedagogical suggestions for English language teachers to increase the effectiveness in ELT. The articles/papers, researches and books written on effective ELT found in electronic sources are studied/overviewed the study. It shows that an effective ELT includes qualified, dynamic and devoted teachers with socio-affective skills, pedagogical and subject matter knowledge, active and creative students, use of sufficient and practical teaching learning materials, proper use of modern equipment and technology, and multiliteracy pedagogy focusing on the cultural diversity of the learners for better ELT.
\end{abstract}

Keywords: effective teachers and learners, modern information technology, multiliteracy pedagogy

\section{Introduction}

The concept of 'effective' is perceived and interpreted differently by various researchers in different fields such as education, medicine, science and law. In spite of different perceptions on effectiveness, what these fields agree that effective means being successful in producing a desired or intended result. Effectiveness also indicates that the degree to which objectives are achieved and the extent to which targeted problems are solved. Likewise, Sammons and Bakkum (2016, p. 11) asserted, "'Effectiveness' is a contested term that can evoke strong emotions because of its perceived links with notions of professional competency and high stakes accountability in some systems".

This is the era of globalization and English has been accepted as the lingua franca of the world. There is great influence of English on language teaching in all over the world. Consequently, there is a marvelous trend in learning English throughout the world. Many institutions and language schools offer various courses on English language learning to make English learners fluent in this language.

Teaching and learning foreign languages has always been an important part of the social life of people. Effective language teaching has become a prominent issue in the field of education as there has been a great demand on learning foreign languages throughout the world. Research has proven that the effective English language teaching has significant value in the foreign language learning. Without effective ELT, the learners cannot learn the language properly. Defining effective teaching, Acheson and Gall (2003, as cited in Uygun, 2013, p. 306) argued as:

Effective teaching involves the ability to provide instruction that helps students to develop the knowledge, skills, and understandings intended by curriculum objectives, create an instructional climate that causes students to develop positive attitudes toward school and self, adjust instruction 
so that all students learn, irrespective of their ability, ethnicity, or other characteristics, manage the classroom so that students are engaged in learning all or most of the time, make sound decisions and plans that maximize students' opportunity to learn, and respond to initiatives for curriculum change so that the new curriculum's intents are fully realized.

In an effective ELT classroom, students learn and demonstrate understanding of meanings rather than merely memorizing facts or events, place priority on reading because it affects success in other content areas and overall achievement gains, and students have higher achievement rates when the focus of instruction is on meaningful conceptualization, especially when it builds on and emphasizes their own knowledge of the world. Bell (2005) opined that it is hard to define effective ELT as it is a complex, multidimensional process that means different things to different people. Uygun, (2013) avowed that an effective English language teacher is the teacher who is clear and enthusiastic in teaching that provides learners with the grammatical (syntactical and morphological), lexical, phonological, pragmatic, and sociocultural knowledge and interactive practice they need to communicate successfully in the target language. The students cannot learn efficiently if the teachers do not teach effectively. To teach successfully the teachers need to be aware on different facets for effective ELT. This paper examines the different facets that are needed to effective English language teaching through observing literature and analysing document.

\section{Methodology}

I have used the document analysis method in this paper since it is theoretical review-based article. Document analysis is a systematic procedure for reviewing or evaluating documents - both printed and electronic (computer-based and Internet-transmitted) material. Bowen (2009) stated that document analysis is a form of qualitative research in which documents are interpreted by the researcher to give voice and meaning around an assessment topic. Analyzing documents incorporates coding content into themes similar to how focus group or interview transcripts are analyzed. Like other analytical methods in qualitative research, document analysis requires that data be examined and interpreted in order to elicit meaning, gain understanding, and develop empirical knowledge (Corbin \& Strauss, 2008).

The methods used for achieving the objective and the tasks of this article are analysis, synthesis, abstraction, induction, deduction and generalization. Mainly data are taken from secondary sources i.e. books, journals articles, dissertation and reports related to English language teaching using library methods visiting library and websites.

\section{Reviews and Discussion}

Gaining insights from literature review and my own experience as an English language teacher, I have made the five themes to discuss for the effective ELT by following document analysis method. These five themes are: a) effective and dynamic teachers, b) active and creative learners, c) effective use of teaching learning materials, d) appropriate use of modern information technology, and e) multiliteracy pedagogy in the classroom. These five themes are the major area that need to be considered for effective ELT in the classroom to develop competence as well as improve performance of the students in English. 


\section{Dynamic and Effective English Language Teachers}

Reflecting on my own experiences in the field of teaching in Nepal I claim that the teachers should be appropriately qualified, carefully selected, and dedicated professionals, who have a wealth of knowledge, experience, and expertise. Dynamic English language teacher should have precise characteristics to achieve successful language teaching. Dincera, Goksub, Takkacc, and Yazicid (2013) argued that a dynamic English language teacher should have all aspects of a teacher including socio-affective skills, pedagogical knowledge, subject matter knowledge and personal qualities. They concluded that the socioaffective skills enable teachers to establish good rapport with their students as well as maintaining the process of education more effectively and successfully. Pedagogical knowledge of teacher supports him/her for providing students with an environment in which they can be relaxed in order to learn and produce well, guiding students, having the ability to organize, explain and clarify, as well as arousing and sustaining interest, motivating students, giving positive reinforcement, allocating more time to preparation and delivery, and teaching with effective classroom materials by integrating technology. Subject matter knowledge enables teacher to make use of audio-visual materials when possible, guide students to get some learning strategies, teach a topic in accordance with students' proficiency levels, and watch and inform students about their progress in language learning. The effective and dynamic teacher should have a sense of humor, be enthusiastic and creative, be tolerant, patient, kind, sensible and open-minded, flexible, optimistic, enthusiastic, having positive attitudes toward new ideas, and other personal characteristics. This review indicates that if the teacher has such characteristics, English language teaching will be effective.

\section{Active and Creative Learners}

An active and creative learner is closely related with successful learner who sets and accomplishes his own goals (Karen, 2001). According to Zamani and Ahangari (2016, p. 70), "Good teaching is clearly important to raising student achievement, if teacher is not aware of the learner's expectation and needs related to the course, it will have negative outcomes regarding the students' performance". Therefore, the teacher should make the students active and creative in course of teaching learning activities. In the same way, the students themselves should be active as well as creative to be smart learners of this era. TESOL International Association (2017, p. 4) has claimed;

Students who actively take advantage of out-of-class study and practice opportunities will make much more long-term progress than students who consider them a chore to deal with as quickly as possible. Students who take responsibility for their own learning will not only improve their language skills more effectively throughout the course but have the agency and skills they need to continue studying after the course ends.

Making learners active and creative means engaging them with materials to work collaboratively with their friends making themselves responsible in the classroom activities. Instead of only listening and memorizing the contents, the learners demonstrate the project works, analyse arguments and try to apply learned concept into a real world situation themselves.

For effective ELT, Hasan, Othman and Majzub (2015) confirmed that active and creative learning 
contributes more benefits to improve students; motivation, attitude, interest and self-esteem which can be used to improve their English language achievement and behavioural changes. Students like and enjoy English class very much because of the various activities provided in the English class. Talking about the importance of outdoor activities, Anderson (2018) opined that students who more actively engage outside the classroom in extracurricular or community activities cultivate friendships and interests which help with broadening language acquisition. The students enjoy in the outdoors activities such as sports, music and art that helps them to be active and creative in learning process. Thus, to make English language teaching effective one, the students should be active and creative to carry out the activities either in the classroom or outside. Active involvement of the students in the various types of language learning activities enable them to be creative which makes them able to learn English language effectively.

\section{Effective Use of Teaching Learning Materials}

Teaching learning materials are the sources that teacher use to deliver instruction in the classroom. Teaching learning materials are important because they can significantly increase student achievement by supporting student learning. Teaching materials can be found in different shapes and sizes, but they all have in common the ability to support students learning. From textbooks, videotapes, and pictures to the internet, teachers rely heavily on a diverse range of materials to support their teaching and their students' learning. The effectiveness of materials used for language teaching depends largely on how meaningful, relevant and motivating they are to the learners. Materials development implies the combination of both reasoning and artistic processes. In this respect, Low (cited in Johnson, 1989) states that "designing appropriate materials is not a science: it is a strange mixture of imagination, insight, and analytical reasoning" (p. 153). Pardo and Tellez (2009, p. 185) emphasized as:

Effective materials make learners feel comfortable and confident because both the content and type of activities are perceived by them as significant and practical to their lives. However, the teaching materials by themselves are not sufficient to create effective teaching and learning settings since a lively EFL/ESL classroom depends largely on good materials used in creative and resourceful ways. Therefore, in the materials designed, language teachers need to lead their students to have materials interact appropriately with their needs and interests in order to facilitate learning.

Following Tomlinson (1998), these materials could be considered effective if they facilitate the learning of a language by increasing learners' knowledge, experience and understanding of it and, simultaneously, helping learners learn what they want and need to learn. In Nepal the students of different backgrounds such as educational, economic, cultural, social and mixed ability come in the classroom to learn English language. In this diverse situation to teach English, there is significant role of teaching materials in Nepal. Thus, in this regard, on the basis of my own practice in teaching English I conclude that the teacher should use teaching and learning materials paying attention on the backgrounds, ability, need and interest of the learners in the classroom. The teacher should involve the students in the activities with the help of the teaching learning materials. The students should work together collaboratively using teaching materials and they themselves become able to learn the contents. The teacher should only play the 
role of facilitator by managing the classroom properly. In this context, Murray (1991) explained that the teacher seems to take the key role in facilitating the students' learning with the help of teaching learning materials and the such characteristics of the teacher may influence the students' learning process to some extents well. Such practice enhances the effective use of teaching learning materials among the students and English language teaching becomes effective.

\section{Appropriate Use of Modern Information Technology (ICT)}

The field of language education is ever changing because of the development of information and communication technology (ICT) in this era. Developments in ICT have become an integral part of our personal and social lives and also influence our professional career. Every sectors of our life is influenced by ICT. In the same way, English language teaching is also affected by the rapid growth in the use of ICT in Nepal. Without using ICT we cannot imagine to teach in the classroom. Wang (2007, p. 1) explained the importance of technology in learning as:

Technology, as a powerful and convenient tool which can provide learners with a rich resource, a visual environment as well as an instructional platform, plays a vital role in language learning. Technology stimulates learning motivation through collaborative learning and it also improves learning efficiency by integrating classroom learning.

Likewise, talking about the significant of ICT in language learning, Mohammadi, Ghorbani, and Hamidi (2011, p. 467) concluded, "as the world progresses, the use of e-learning, electronic devices, internet, computers in teaching and learning process increases too and we have to synchronize ourselves with it and increase our abilities to be able to work with technologies to increase our knowledge". Zamani and Mohammadzadeh (2013, as cited in Golshana \& Tafazolib, 2014) showed that most of students like online social networks and online social networks can be used to facilitate English language learning. Technology provides opportunities for interaction, allows for immediate feedback, increases learner autonomy, simulates real-life situations and experiences through video, audio, and graphics.

The use of ICT in the classroom has changed the roles of students and teachers. The role of the teacher is shifting from transmitter of knowledge to a facilitator of participants in the learning process together with the student. In the same vein, students should be more responsible for their own learning as they seek, find, synthesize, and share their knowledge with other peers. Regarding the appropriateness of ICT for effective ELT in the context of Nepal, Pun (2013, p. 29) concluded:

The use of ICT in language teaching promotes students' motivation and learning interest in the English language. If students are too dependent on their mother tongue, they should be motivated to communicate with each other in English through the use of ICT. The utilization of ICT can fully improve the students' thinking and practical language skills and, thus, it can be used effectively in the English language teaching classrooms for non-native speakers of English in the context of Nepal.

\section{Multiliteracy Pedagogy in the Classroom}

In recent years, educators, researchers, policymakers and other educational stakeholders have been 
engaged in an ongoing dialogue about the need for students to develop a broad repertoire of literacy practices that are not confined to traditional views of literacy and traditional approaches of literacy instruction (Rajendram, 2015, p. 1). The focus on language education in the 21 st century is no longer on grammar, memorization, and learning from rote, but rather using language and cultural knowledge as a means to communicate and connect to others around the globe (Eaton, 2010). The New London Group (1996) has proposed the concept of multiliteracy, which views literacy as continual, supplemental, and enhancing or modifying established literacy teaching and learning rather than replacing traditional practices (Rowsell, Kosnik, \& Beck, 2008 as cited in Benjamin, 2014). The integration of teaching multiliteracy has a potential to adopt new ideas and overcome the limitations of traditional learning approaches in the $21^{\text {st }}$ century literacies.

Biswas ( n. d.) expressed that multiple literacies imply multimodal ways of communication, which include communications between other languages, using language within different cultures, and an ability to understand technology and multimedia. Symbols, audios, videos, billboards, or emails/listserv, for example, are integrated to the social and education media. Moreover, students learn to collaborate by sharing their thoughts with others in online spaces where they can engage in different form or modes (texts, video, image, rhymes, and poetry) of learning processes. Consequently, we can expect students to become more confident and knowledgeable in their learning context through participatory and collaborative practices. Benjamin,(2014, p. 116) mentioned:

The New London Group (1996) advocates for a multiliteracy pedagogy that includes four components: situated practice, overt instruction, critical framing and transformed practice. Situated practice draws on experience of meaning-making in specific contexts,. Overt instruction develops an explicit meta-language to support active interventions that scaffold student learning. Critical framing makes sense of situated practice and overt instruction by interpreting the social contexts and purposes related to meaning making. The goal is to enact transformed practice where students, as meaning makers, become designers themselves and not just consumers.

The multiliteracy pedagogy envisages teachers as facilitators in classrooms that are rich with studentmediated collaborative learning activities (McClay, 2006). Today's students must possess multiple literacy skills that can enable them to utilize the potential of the diverse modes of communication offered by new technologies (Chatel, 2002).Reflecting on my own experience teaching English in community school, I can say that the students who come from different linguistic backgrounds to study English in the classroom feel difficult to learn because of the medium of instruction. In this situation, the medium of instruction is English and they do not know it and also they are not allowed to use their native language in the classroom. Thus, they become poor in English, in this sense, if the teachers apply multiliteracy pedagogy by providing opportunity for them to use their own native language and the language of medium of instruction, they can learn English by sharing their ideas with other friends. Therefore, as Nepal is a multilingual and multicultural nation, multiliteracy pedagogy is very much important to make English language teaching effective to make the learners able to learn English. 


\section{Conclusion and Implications}

The findings from the relevant studies indicate that for effective English language teaching at present era ,there should be effective and dynamic teachers, active and creative learners, effective use of teaching materials, appropriate use of modern information technology, and multiliteracy pedagogy in the language teaching process.

Regarding effective and dynamic teachers, the findings reveal that the effective language teacher should be enthusiastic to teach English, have good relationships with students, care students' needs about English and motivate students by creating autonomy supportive environments within which students can motivate themselves. According to the studies, active and creative learners can accomplish their own goals successfully. They work collaboratively with their friends making themselves responsible in the classroom as well as outdoor activities. Concerning the effective use of teaching learning materials the study reveals that effective materials make learners feel comfortable and confident because both the content and type of activities are perceived by them as significant and practical to their lives. The teaching learning materials could be considered effective if they facilitate the learning of a language by increasing learners' knowledge, experience and understanding of it.

As for the appropriate use of modern information technology, it is found that ICT stimulates learning motivation through collaborative learning and it also improves learning efficiency by integrating classroom learning. The use of ICT in language teaching promotes students' motivation and learning interest in the English language. The role of the teacher is changed from transmitter of knowledge to facilitator being a participant in the learning process with the student. Similarly, students should be more responsible for their own learning as they search for, discover, produce, and allocate their knowledge with their friends. Exploring the concept of multiliteracy pedagogy in the classroom in the context of Nepal, it is exposed that the integration of teaching multiliteracy as classroom pedagogy has a potential to adopt new ideas and overcome the limitations of traditional learning approaches. Multiliteracy implies multimodal ways of communication between the language of medium of instruction and the languages of the learners within different cultures along with an ability to understand technology and multimedia. In multiliteracy pedagogy students learn to collaborate by sharing their thoughts with others in online spaces where they can engage in different form or modes (texts, video, image, rhymes, and poetry) of learning processes.

Research pointed out that dynamic teachers, active and creative learners, effective use of teaching learning materials, appropriate use of modern information technology, and multiliteracy pedagogy in the classroom are necessary for effective English language teaching. In addition, many different studies' views about what constitutes an effective ELT mostly matched each other even though the degree of their agreement on the common factors is a bit different. Finally, the concept of an effective ELT consists of a balanced combination of above five main aspects. As the popularity of English is expanding day by day and worldwide, the teachers of English feel the need of change in their language teaching perceptive. To teach English language effectively in the classroom the teachers should be conscious to be familiar with the facets that are discussed in the article. 


\section{References}

Anderson, M. (2018 Aug 3). 6 qualities of successful ESL teachers. Retrieved from: https://www. teachthought.com/pedagogy/6-qualities-of-successful-esl-teachers

Bell, T. R. (2005). Behaviors and attitudes of effective foreign language teachers: Results of a questionnaire study. Foreign Language Annals, 38 (2), 259-270.

Benjamin, B. (2014). Multiliteracies in the classroom: Emerging conceptions of first-year teachers. Journal of Language and Literary Education, 10 (1), 114-135. Retrieved from: https://files.eric. ed.gov/fulltext/EJ1030724.pdf

Biswas, S. ( n. d.). How to tech multiliteracies? Retrieved from: https:/www.teacherresearch.ca/detail/ post/how-to-teach-multiliteracies

Bowen, G. A. (2009). Document analysis as a qualitative research method. Qualitative Research Journal, 9 (2), 27- 40. doi:10.3316/QRJ0902027

Chatel, R. G. (2002). New technology, new literacies: Creating a bridge for English language learners. The NERA Journal, 38 (3), 45-49.

Corbin, J. \& Strauss, A. (2008). Basics of qualitative research: Techniques and procedures for developing grounded theory (3rd ed.). Thousand Oaks, CA: Sage.

Dincera, A., Goksub, A., Takkacc, A., \& Yazicid, M. (2013). Common characteristics of an effective English language teacher. The International Journal of Educational Researchers, 4 (3), 1-8. Retrieved from: http://www.eab.org.tr/public/ijer/4/3/a_dincer.pdf

Eaton, S. E. (2010). Global trends in language learning in the twenty-first century . Calgary, Canada: Onate Press.

Golshana, N., Tafazolib, D. (2014). Technology-Enhanced Language Learning Tools In Iranian EFL Context: Frequencies, Attitudes And Challenges Procedia - Social and Behavioral Sciences, 136, 114-118. doi: 10.1016/j.sbspro.2014.05.299

Hasan, A., Othman Z.,\& Majzub, R. M. (2015).Using active, creative, effective and joyful (ACEJ) learning strategies toward English achievement and their behavioural changes among primary school students. Mediterranean Journal of Social Sciences, 6 (6), 455-459. Doi:10.5901/mjss.2015.v6n6p455

Johnson, R. K. (1989). The second language curriculum. In Appropriate design: The internal organisation of course units. Chapter 9. Cambridge: Cambridge University Press.

Karen, S. (2001). First year experiences series: Being a more effective learner. University of Sidney Learning Centre Publishing. Australia: Sidney. Retrieved from: http://sydney.edu.au/stuserv/ documents/learning_centre/EffectiveLearner.pdf

McClay, J. K. (2006). Collaborating with teachers and students in multiliteracies research: "Se hace camino al andar". The Alberta Journal of Educational Research, 52(3), 182-195.

Mohammadi, N., Ghorbani, V , \& Hamidi, F. (2011) .Effects of e-learning on Language Learning Procedia Computer Science, 3, 464-468. Retrieved from: https://core.ac.uk/download/pdf/82127949.pdf

Murray, H. G. (1991). A time for local perspectives. In J. Murphy and P. Byrd (Eds.), Understanding the course we teach: Local Perspectives on English Language Teaching,3-10. Ann Arbor: University of Michigan Press.

New London Group. (1996). A pedagogy of multiliteracies: Designing social futures. Harvard Educational 
Review, 66 (1), 60-92.

Pardo, A. N. \& Tellez, M. F. T. (2009). ELT Materials: the key to fostering effective teaching and learning settings. Profile: Issue in Teachers' Professional Development, 171-186. Retrieved from: https:// revistas.unal.edu.co/index.php/profile/article/view/11449/36802

Pun, M. (2013). THE use of multimedia technology in ENGLISH language teaching: A global perspective. Crossing the Border: International Journal of Interdisciplinary Studies, 1(1),15. Retrieved from: https://www.nepjol.info/index.php/CTBIJIS/article/view/10466

Rajendram, S. (2015). Potentials of the Multiliteracies Pedagogy for Teaching English Language Learners (ELLs): A Review of the Literature. Critical Intersections in Education: An OISE/UT Students' Journal,3, 1-18. Retrieved from: file://E:/NANI\%20BABU/Article/Collection\%20for\%20Articles/ Multiliteracy/26307-Article\%20Text-61942-1-10-20161104.pdf

Sammons, P. \& Bakkum, L. (2016). Effective teaching. Retrieved from: https://www. educationdevelopmenttrust.com/EducationDevelopmentTrust/files/98/98ad6340-0ef6-4e1d-a541db6018afce7d.pdf

TESOLInternationalAssociation.(2017). Principles oflanguage learning and the role of the teacher. Retrieved from: https://www.tesol.org/docs/default-source/books/14077_sam.pdf?sfvrsn=2\&sfvrsn=2

Tomlinson, B. (1998). Materials development in language teaching. Cambridge: Cambridge University Press.

Uygun, S. ( 2013).How to become an effective English language teacher. Journal of Educational and Social Research, 3 (7) 306-311. doi:10.5901/jesr.2013.v3n7p306

Wang, Y. J. (2007). Are We Ready? A Case Study of Technology-enhanced, Collaborative Language Learning. Proceedings of the World Congress on Engineering and Computer Science. Retrieved from: http://www.iaeng.org/publication/WCECS2007/WCECS2007_pp499-503.pdf

Zamani, R. \& Ahangari, S. (2016). Characteristics of an effective English language teacher (EELT) as perceived by learners of English. International Journal of Foreign Language Teaching \& Research, 4 (14), 69-88. Retrieved from: http://jfl.iaun.ac.ir/article_17138_72021c12d9759a235038699132c 8f008.pdf

Nani Babu Ghimire is a Lecturer at Siddha Jyoti Education Campus Sindhuli, Tribhuvan University, Nepal. He has completed Master's Degree in English Education and English in Arts from TU. He is currently a Ph. D. Scholar in English Education under Graduate School of Education at TU. He is more interested in the studies related to teacher professional development, multilingualism and diversity in language education including critical pedagogy. He is a Life member of NELTA and Advisor of NELTA Sindhuli. 